EPiC Series in Engineering
Volume 3, 2018, Pages 1927-1934
HIC 2018. 13th International
Conference on Hydroinformatics

\title{
A study of public safety engineering projects for the improvement of drinking water quality in northwestern China-an example from Shanshan County, Xinjiang
}

\author{
Weiwei Shao ${ }^{1}$, Jiahong Liu ${ }^{1 *}$, Denghua Yan $^{1}$, Haixing Zhang ${ }^{2}$, Zhaohui \\ Yang ${ }^{1}$, Guiyu Yang ${ }^{1}$ and Fenfen Liu ${ }^{3}$ \\ ${ }^{1}$ State Key Laboratory of Simulation and Regulation of Water Cycle in River Basin, China \\ Institute of Water Resources and Hydropower Research, Beijing 100038, China \\ ${ }^{2}$ North China Municipal Engineering Design \& Research Institute Co. Ltd., Beijing Branch, \\ Beijing 100081, China \\ ${ }^{3}$ Jiangsu Maymuse Environmental Protection Technology Co. Ltd., Changzhou 213000, China \\ shaowweiwhr.com, liujh@iwhr.com, yandh@iwhr.com, \\ zhx112700@163.com, yzh2010@iwhr.com, guiyuy@iwhr.com, \\ lffemaymuse.com
}

\begin{abstract}
Using Shanshan County as the research focus, this study investigates drinking water safety in northwestern China and proposes measures for improving the efficiency of clean water projects targeting drinking water quality in the region. As new technologies such as the Internet and the Internet of things gain wider usage, urban and rural safe drinking water projects should focus on equipping projects, modularizing the equipment, improving project management using internetization, and developing intellectualization for increased Internet dependence. This study proposes modularization of the equipment for clean water projects for centralized and decentralized water supply programs. For management of such projects, this research proposes internetization in project management as well as intellectualization of construction, including establishment of management facilities, automation of water plant operations, intelligent control of clean water operations, and online intelligent water monitoring. This study integrates various information resources and investigates the implementation of intellectualized management of water treatment facilities through scientific advances and evaluates the potential of these approaches for increasing the quality of public service.
\end{abstract}

\footnotetext{
* Corresponding author: 1iujh@iwhr.com
} 


\section{Introduction}

Ensuring the quality of drinking water in cities is a basic requirement and represents a fundamental right $(\mathrm{Xu}, 2014)$. At present, the drinking water situation faced by cities in Northwest China is grim; existing projects focusing on water safety in urban and rural areas are relatively limited in scale and are constrained by issues such as low construction standards, limited water quality monitoring, and a lack of operational mechanisms (Sun et al., 2014). According to the national standards, the rate of implementing water safety projects in regions in Northwest China must be increased considerably to ensure adequate water supply and quality and to improve the long-term operation of engineering projects for providing social services. To keep up with national urban and rural development and to ensure a prosperous society for protection of drinking water safety, it is critical to hasten the implementation of urban and rural drinking water safety projects in Northwest China, strengthen the protection of water sources and water quality, and improve the operation mechanism, social service system, and living conditions and health of residents. This case study in Shanshan County, Xinjiang, investigates approaches for improving the quality and efficacy of water safety facilities in rural and urban areas. Moreover, it examines the application of communication technology for automation of water plant operations, intelligent control of clean water operations, and the use of online intelligent monitoring during the construction of water safety facilities to advance the development and modularization of equipment, internetization of management, and intellectualization of internetization in the allocation of resources to ensure the safety of drinking water in Shanshan County.

\section{Material and Methods}

\subsection{Study Area}

\begin{tabular}{|c|c|c|}
\hline \multirow[b]{2}{*}{ Department } & \multicolumn{2}{|r|}{ Shanshan County } \\
\hline & $\begin{array}{r}\text { South of Tian Shan } \\
\text { Mountains }\end{array}$ & $\begin{array}{r}\text { North of Tian Shan } \\
\text { Mountains }\end{array}$ \\
\hline Annual average precipitation $(\mathrm{mm})$ & 17.6 & 25.3 \\
\hline Annual average evaporation (mm) & 3216.16 & 2751 \\
\hline Annual average temperature $\left({ }^{\circ} \mathrm{C}\right)$ & 14.4 & 11.3 \\
\hline Average temperature in July $\left({ }^{\circ} \mathrm{C}\right)$ & 33 & 29.2 \\
\hline Average temperature in January $\left({ }^{\circ} \mathrm{C}\right)$ & -9.8 & -11.2 \\
\hline Annual sunshine hours $(\mathrm{h})$ & 2957.7 & 3122.8 \\
\hline Annual total radiation $\mathrm{kcal} / \mathrm{cm}^{2}$ & \multicolumn{2}{|c|}{150.4} \\
\hline$\geq 10^{\circ} \mathrm{C}$ accumulated temperature $\left({ }^{\circ} \mathrm{C}\right)$ & 5548.9 & 4525.5 \\
\hline Frost free period (d) & 224 & 192 \\
\hline Maximum permafrost depth $(\mathrm{cm})$ & \multicolumn{2}{|c|}{90} \\
\hline Maximum wind speed $(\mathrm{m} / \mathrm{s})$ & \multicolumn{2}{|c|}{29} \\
\hline Average wind speed $(\mathrm{m} / \mathrm{s})$ & \multicolumn{2}{|c|}{4.8} \\
\hline Wind direction & & Northwest \\
\hline
\end{tabular}

Table 1: Main meteorological elements in Shanshan County

This study focuses on Shanshan County in the Xinjiang Uygur Autonomous Region, located in the eastern section of the Tian Shan Mountains near the southern base of the Bogda Peak and east of the Turpan Depression. The area is located in a temperate zone, and its climate is inland desert; the region 
receives an annual average of rainfall 17.6-25.3 mm. At the end of 2014, the population was 242,700. The main hydrometeorological elements in Shanshan County are given in Table 1. In urban regions, the water supply is sourced from the Shanshan No. 1 Water Supply \& Drainage Company and the Shanshan No. 2 Water Supply \& Drainage Company. The rural regions rely on a centralized water distribution including four water plants: Shan-nan Water Work, Qiketai Water Work, Suburban Water Work, and Lianmuqin Water Work. The task of ensuring the drinking water quality in Shanshan County is complex; an estimated 41,600 thousand people in towns and townships currently do not have access to safe water mainly because water quality standards are not met. The results from water quality inspections conducted in two consecutive years (2013-2014) show that the bacteria levels exceeded the safety limits in drinking water supplied to $80-85 \%$ of the population in the county. In addition, turbidity, coloration, chloride, and hardness indicators also exceeded the safe limits, indicating that the water purification methods are relatively primitive and lack automation ( $\mathrm{Li}$ et al., 2011).

\subsection{Data and methods}

This study conducted a survey using indicators reflecting the social and economic conditions in Shanshan County and employed data on the development and usage of water resources such as the statistical yearbooks of Turpan and Shanshan, reports on the safety and development of water facilities in Shanshan County, provincial development plans, and plans for provincial water treatment plants. These data were used in conjunction with field research data.

Using the current state of water resources in Shanshan County as a base, this study established an adequate water supply network aimed to optimize the water resources and facilities and considered the terrain, hydrological conditions, and differences in the quality of the existing water supply works. In addition, it developed improvements to address the weaknesses of the existing facilities. These measures include modularization of the distribution of clean water facilities, automation and increased dependence on intelligent control, utilization of new technologies and methods to achieve the modularization and internetization, and intellectualization of management with the goal of improving drinking water safety across the region (Yang et al., 2014).

\section{Results and Discussion}

\subsection{Equipment and modularization of clean water projects}

Studies of existing clean water facilities have shown that the centralized and decentralized water supply programs are insufficient in scale, provide insufficient amounts of stored water, lack intelligent control of the water treatment process, and result in a substandard water supply. In addition, the water processing technology is primitive and ineffective in dealing with changes in water quality and the associated risks owing to water pollution. Merging several water processing facilities is appropriate for regions where water sources are diffused and inadequate, where water pollution may occur, where manpower and resources may be lacking, or where the local economy may be underdeveloped. In a modular design, different technologies can be combined on the basis of differences in water quality and construction to account for pollution issues such as high levels of organic matter, salt, and turbidity. The space optimization resulting from the use of different modules allows for a high degree of integration and minimizes the occupied surface area. Compared with traditional centralized water supply programs, modularly integrated water processing facilities have benefits of high efficiency, energy savings, and ease of management (Figure 1). 


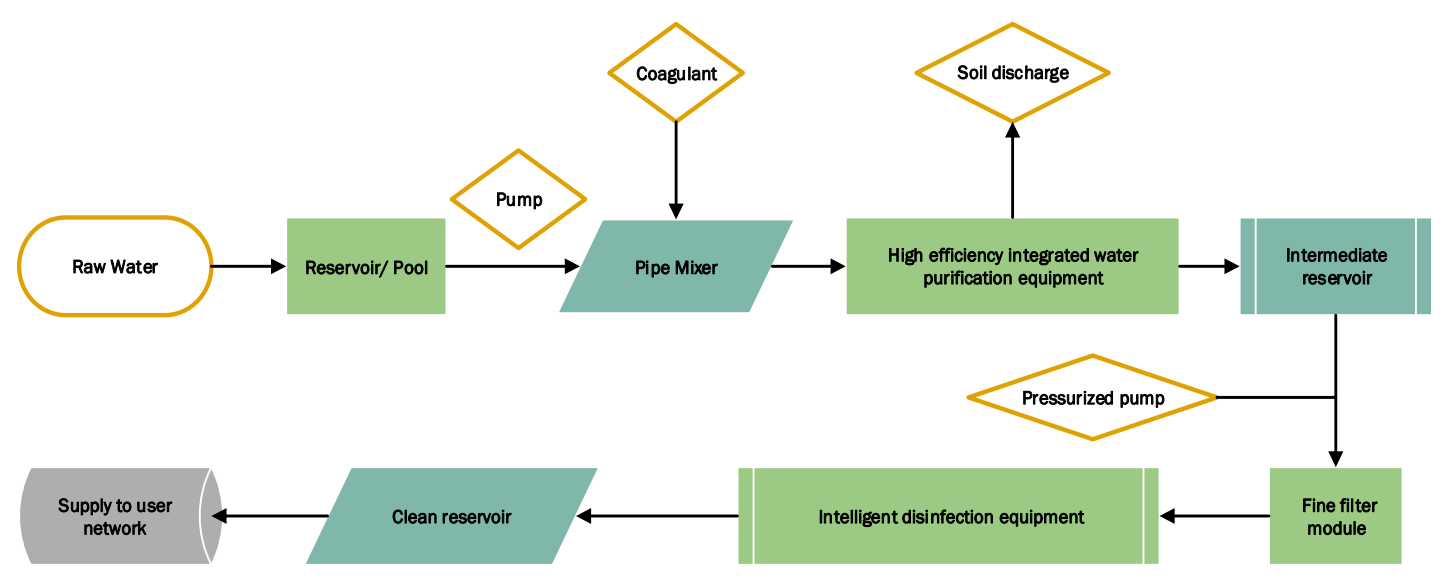

Figure 1: Processing flowchart for a centralized water supply program

A centralized water supply plan allows the selection of a water source with standard water quality and stable water volume, which enables more effective management. In Shanshan County, with a large water supply, construction of a centralized water supply mode was adopted for the project. In this system, the raw water in the water source area enters the reservoir through the water intake structure, and the cistern plays the main role of regulating the water quality and quantity. During the flood season, the reservoir can also be used as a grit chamber. A particular amount of coagulant is added to the front end of the pipeline mixer. The colloid, suspended solids, microorganisms, and small amounts of organic and inorganic pollutants in the raw water are flocculated into larger particles and alum flowers by adsorption of the electric layer and the bridge under the action of the coagulants. The water treatment process of colloids, suspended solids, solid particles and impurities, microorganisms, organic and inorganic pollutants such as flocculation reactions combined with efficient separation, sedimentation, filtration, and reduced water turbidity results in clear and transparent water after mixing the flocculation water into the efficient integrated water purifier. The equipment parts include mixing, reaction, clarification, filter, flushing, sludge discharge, and the starting point. The entire operation process can enable automatic operation without the need for personnel, which is important for realizing automation management of the water plant. To further protect the follow-up processing unit, the middle of the pool plays a major role in the regulation of water inflow to the water pump intermediate pool after lifting into the subsequent processing unit. The filtration process of the ultrafiltration membrane is based on the pressure difference between the two sides of the membrane as the driving force and the ultrafiltration membrane as the filter medium. Under a given pressure, when the raw liquid flows through the membrane surface, many tiny pores that are covered with the ultrafiltration membrane allow only water and small molecules to pass through the membrane. However, the volume in the original solution is larger than that on the surface of the membrane, and this water is trapped on the liquid inlet side of the membrane and becomes the concentrate. Therefore, purification, separation, and concentration of the raw liquid are achieved. In addition, the automatic disinfection device uses mainly chlorine dioxide to achieve sterilization by killing bacterial brew, bacterial spores, fungi, mycobacteria, and viruses.

Decentralized water supply programs target the treatment of specific regional pollutants and focus on establishing water treatment plants and management networks that serve individual villages, thus achieving the purpose of a dual water supply. Measures that target specific water quality issues include the treatment of high-chlorine water and brackish water and the removal of iron, manganese, and other pollutants. 


\subsection{Internetization and intellectualization of facility management}

With the development and application of new information technology such as the Internet of things, Internet, and cloud computing, water informatization has become an important part of intelligent management in cities and signifies the informatization level of urban management. The construction of internetization and intellectualization in the Shanshan drinking water safety protection project is of great significance for integrating information resources, scientifically and efficiently realizing drinking water safety management and improving the residents' quality of life.

\subsubsection{Management structure}

The Public Water Affairs Bureau in Shanshan County needs to establish an information center for water safety to serve as the control headquarters of intellectualization measures across the region. The internetization and intellectualization of the water safety protection project for Shanshan County involves two water works: Shanshan County No. 1 Water Supply \& Drainage Company and Shanshan No. 2 Water Supply \& Drainage Company. Four subordinate waterworks involved in managing the general station of rural tap water construction include the Shan-nan Water Work, Qiketai Water Work, Suburban Water Work, and Lianmuqin Water Work. The information center is equipped with management calculators and data servers to integrate and monitor data from the six water plants in the region. The data include operational, water quality, and video surveillance data, which are used for the monitoring and development of official network statistics to provide water safety information to the respective regions in the county. In addition, one central control room exists in each water plant.

\subsubsection{Automated control systems for water plant operation}

Automatic control systems are installed in six water works in Shanshan County. Such systems and high-performance programmable controllers are employed in the operation of the water plants, representing a safe and stable industrial network control system. The system is composed of several terminals displaying data for intelligent water intake, water processing, and water supply; water quality and centralized monitoring; and water usage control. First, an intelligent water intake terminal needs to be installed at the water intake or water intake terminal of the water plant. This intelligent water intake terminal monitors and protects the water intake equipment in real time and transfers the water from the water source or the water intake to the purification system of the water plant. Second, an intelligent water system terminal needs to be installed in the water purification system of the water plant. Combined with process requirements and automatic intelligent regulation of water purification equipment operation and real-time monitoring and water protection equipment, the intelligent water system terminal ensures an adequate water volume and effluent quality of the water purification equipment. Subsequently, the water supply terminal of the water plant should be equipped with an intelligent water supply control. The intelligent control water supply equipment conveys the qualifications of water to the water user through a constant pressure or a constant flow rate, which meets the water demand of the water user and ensures monitoring and protection of the water supply equipment in real time. Next, an intelligent water quality monitoring system needs to be installed in the water intake, water supply, and pipe network of the water plant. Water quality monitoring at the terminal in real time ensures the safety of the water intake, water supply, and drinking water. In addition, a monitoring terminal of the pipe network needs to be installed in the water supply network of water plant. This enables the running data of the pipe network to be transferred back to the central control room in real time to evaluate its status. Analysis of this data enables the central control room to effectively manage the water supply and its pressure. Finally, the water control terminal is used to monitor the water pressure and flow in real time to ensure that the water needs of the users are met. 


\subsubsection{Intelligent control of the water purification process}

Intelligent control of the water purification process combines automated technology with intelligent management and monitoring technology to form an integrated solution linking the water treatment plants (Zhang et al., 2014). The specific functions include real-time data displays of water quality parameters at the groundwater sources, real-time monitoring of production, graphic displays and inquiries, production report management, police alerts, and incident management. The most important of these is the real-time monitoring of production.

The water purification process of the purification equipment is presented in a dynamic image on a computer monitor for real-time monitoring of the six water plants in the county. Changes in the water quality index, process parameters, running condition of the equipment, and the direction of water supply flow are shown during the purification process of the water plant. Through a wide range of pressure monitoring points and flow monitoring points, the pressure distribution of the water supply network and the variation of water demand caused by various disturbance factors can be comprehensively reflected in the field process flow on the dynamic monitoring screen. This enables the running state and data of water intake, water production, and water supply in the water plant to be evaluated accurately in real time. A schematic diagram of the real-time monitoring and control system is shown in Figure 2.

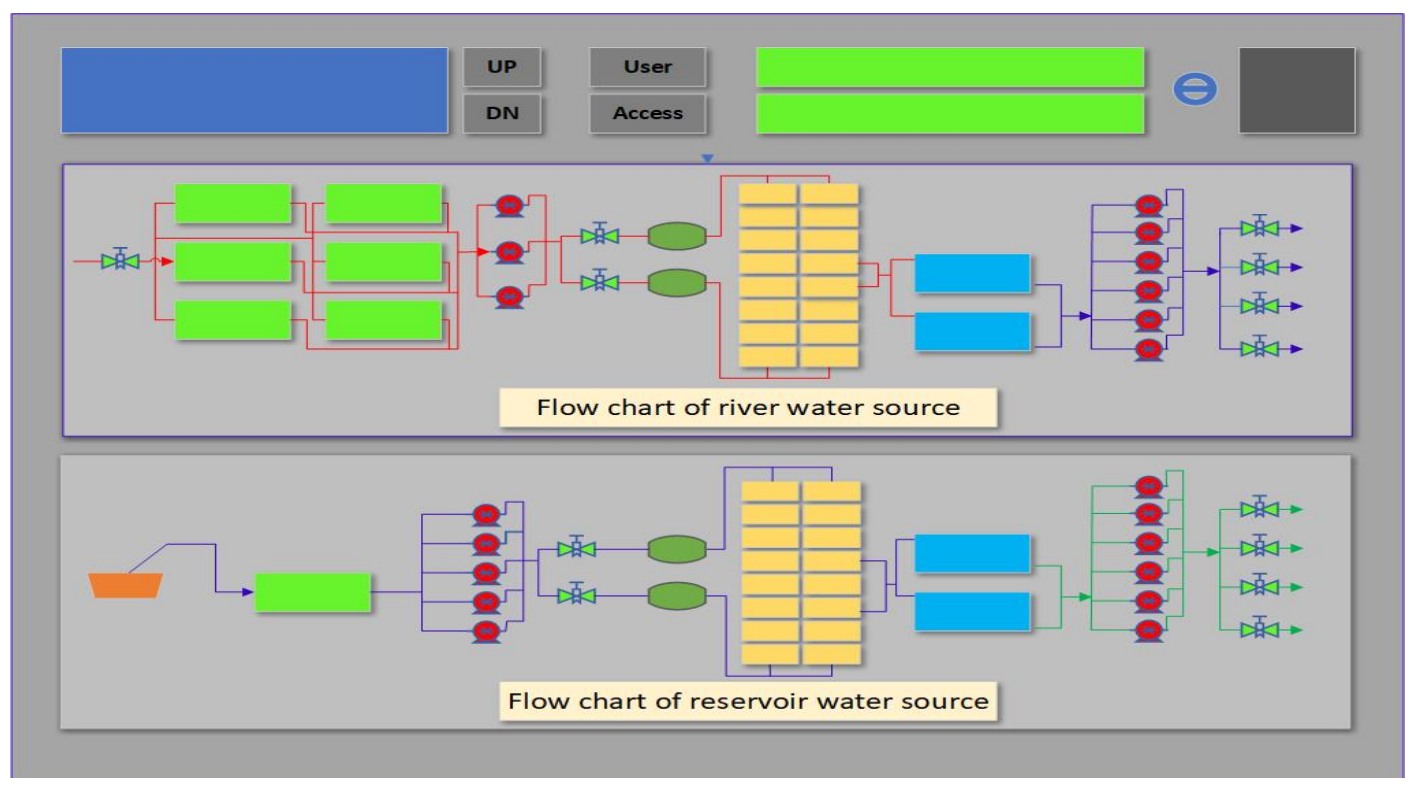

Figure 2 : Schematic of real-time monitoring and control system

\subsubsection{Online monitoring of intelligent water treatment facilities}

The online monitoring systems of the intelligent water treatment facilities are organically combined with the Internet of things and intelligent water systems to increase the management automation. Examples of the monitored parameters include online monitoring of water source wells, water supply quality, and central water supply networks (Wang et al., 2016). The control rooms in the six water plants in Shanshan County are equipped with centralized information dispatch centers. By implementing daily centralized data collection and a timely dispatch of the next day's indicators, the overall water supply is maintained to prevent waste or insufficient supply. The online surveillance 
systems of the intelligent water treatment facilities also include police alerts in the case of pollution events as well as emergency protocols to ensure water safety and quality across the county.

\section{Intelligent water monitoring project}

The online monitoring system of intelligent water affairs includes the online monitoring of water quality in the water source well, water quality in water supply, and water supply network. The online monitoring system of water quality in the water source well enables real-time monitoring in the water source of a water plant allocated in Kanerqi, Kekeya, and Ertanggou water source areas and supplies feedback to the central control room network of the smart water platform. In addition, the information of the water quality pollution is sent to the designated staff for the first time. Thus, the intelligentization and timeliness of water management can be improved effectively, and intelligent, networked, and real-time water environment monitoring is realized ( $\mathrm{Li}, 2014)$. Other monitoring parameters such as water intake volume, outlet pressure, water quality turbidity, water quality conductivity, water quality $\mathrm{pH}$, water quality temperature, dissolved oxygen, and water toxicity are also monitored to ensure effective water intake and water safety from the source. The water quality is monitored online, and these parameters in addition to others such as the water level of the supply pool and the residual chlorine need to be evaluated to ensure the water supply safety of six water plants in Shanshan County. In the online monitoring of this water plant network, the pressure, flow rate, water quality change, and the residual chlorine at the end of the pipes are also monitored in real time. This enables evaluation from a remote location to determine whether the pipe network is abnormal, whether the pressure and flow of the water supply are satisfied, and whether secondary pollution is present in the pipe network (Cuevas et al., 2017). This system could provide data support for water quality improvement in the future.

\section{Function of online monitoring system for intelligent water affairs}

The function of the online monitoring system of intelligent water affairs is to create an information-based center for efficient dispatching and early warning and emergency management of the pollution events. The water plant control center for the six Shanshan County plants includes a dispatching center information platform involving daily pipe network data collection and timely issue of the next day's indicators to ensure that the total water demand is balanced to avoid waste or insufficient water supply. Through various illustrations, the proportion of the power consumption and the consumption of the raw water is analyzed, and a comprehensive energy consumption index is obtained. By using these data, a scheduling scheme is generated to assist the water plant operator in managing the water supply and water network in the area. Moreover, data sharing is achieved through the network, and production scheduling data are directly sent to the office automation system to integrate monitoring, control and management, improved production efficiency, and enhanced economic benefits.

The online monitoring system for intelligent water affairs includes a superior warning and emergency management mechanism for pollution events. The Internet of things module combined with the water supply network, spatial data, and attribution data of the drainage basin are integrated with advanced computer software technology, communication technology, and graphics processing technology to establish a timely and stable alarm and emergency management system. When a river basin incurs a pollution discharge event, the first notice of the event is sent in real time through a computer network, acousto-optic signal, short message, or other means. Such a measure can provide specific information of the pollution area through a geographic information system (GIS) to inform relevant departments in sufficient time to apply measures. The large amount of data is used to conduct statistical analysis of the water quality data to provide decision support for water pollution events and to ensure the safety of water consumption in Shanshan County (Dao et al., 2017). 


\section{Conclusions}

This study investigated the efficiency measures implemented for water safety and quality in Shanshan County and proposed measures for increased efficacy and the protection of water purification projects to target the issues of substandard water source quality, insufficient management ability, and other related problems. The proposed measures include a combination of automation, internetization of management, and intelligent monitoring technology. New technology and methodologies should be used in the implementation of water safety measures in Northwest China, and information technology should be integrated to achieve scientific, highly efficient, and intelligent management, thereby increasing the quality of public service and the living standards of the population. According to past experiences during the construction of rural drinking water safety projects and the actual situation of Shanshan County, the current water supply safeguard measures of this region do not meet the demands of increased urban development; therefore, the measures should be significantly improved to ensure water safety. The Shanshan County drinking water source protection area is still in the initial stage. To ensure that this region can provide long-term safety of drinking water for residents, more basic investigation, research, and management should be conducted, and external sources should be actively sought to provide water source protection.

\section{Acknowledgements}

The researchers would like to extend their thanks to the Chinese National Key Research and Development Program (2016YFC0401401) and Chinese National Natural Science Foundation (Nos. 51522907 and 51109222). The study was also supported by the Research Fund of the China Institute of Water Resources and Hydropower Research (Nos. WR0145B502016 and 2017ZY02).

\section{References}

Xu, Y. (2009). graphicx: Analysis on Caofeidian water purification project water purification pland design technology characteristic, Shanxi Architecture (pp.197-198).

Sun, Y., Wang, H., Zhang, T. (2014). graphicx: A case study of townlet water purification engineering design, Water Supply \& Drainage Engineering (pp.97-99).

H. Li. (2011). graphicx: Influence of urban and rural drinking water safety project in Guyuan region of Ningxia on water use in Pingliang city, Water Resources Protection (pp.90-94).

Yang, M., Jiang, Y., Tian, Y., Wang, H. (2014). graphicx: Demand analysis of smart water resources. J. Tsinghua Univ. (Sci \& Technol) (pp.133-136).

Zhang, X., Tang, M., Liu, M., Wang, H. (2014). graphicx: Conception of wisdom water affair construction in Beijing, Water Resources Informatization (pp.64-68).

Wang, J., Yang, J. (2016). graphicx: Spatial analysis of rural drinking water safety environment in Xinjiang based on GIS, Xinjiang Water Resources (pp.10-12).

Li, W. (2014). graphicx: Study of Rural Drinking Water Safety Engineering Management, Applied Mechanics and Materials (pp.558-561).

Cuevas, V., Gatica, L., Jaime, H., Palacios, G. (2017). graphicx: A Probabilistic Model to Estimate Cost of Drinking Water Projects in Rural Areas. Advanced Engineering Forum (pp.537-543).

Dao, A., Nguyen, D., Han, M. (2017). graphicx: Design and operation of a rainwater for drinking (RFD) project in a rural area: case study at Cukhe Elementary School, Vietnam, Journal of Water, Sanitation and Hygiene for Development (pp.651-658). 